\title{
Atividade lúdica e sua importância na hospitalização infantil: uma revisão integrativa
}

\author{
*Maria BenegelaniaPINTO1 \\ Luciana Dantas Farias de ANDRADE ${ }^{1}$ \\ Ana Paula Gomes de MEDEIROS ${ }^{2}$ \\ Genalda Liliane de Oliveira SANTOS ${ }^{2}$ \\ Renata QUEIROZ \\ Renata Dantas JALES ${ }^{2}$
}

\author{
${ }^{1}$ Professoras da Unidade Acadêmica de Enfermagem, Universidade Federal de Campina Grande, Cuité-PB, Brasil. \\ ${ }^{2}$ Acadêmicas do curso se enfermagem, Universidade Federal de Campina Grande, Cuité-PB, Brasil. \\ "E-mail para correspondência: benegelania@yahoo.com.br
}

Recebido em: 17/04/2015 - Aprovado em: 25/08/2015 - Disponibilizado em: 30/10/2015

\begin{abstract}
Resumo:Trata-se de uma revisão integrativa da literatura que objetivou analisar e caracterizar o que os estudos científicos publicados em periódico da área da saúde do ano de 2010 a 2014, apontam acerca da utilização do lúdico durante a hospitalização de crianças. A pesquisa foi realizada no período de Agosto à Dezembro de 2014. Na busca às bases de dados indexadoras SciELO, LILACS, foram utilizados os descritores "Ludoterapia", "hospitalização" e "criança", conforme orientação do Descritores em Ciências da Saúde da Biblioteca Virtual em Saúde. De acordo com os artigos analisados pode-se constatar que o lúdico é de fácil aplicação e se faz necessário para amenizar ou eliminar os traumas que a hospitalização acarreta ao individuo, sendo uma prática que abrange diversas formas variando desde o estabelecimento de uma conversação até o uso de instrumentos como o brinquedo e o desenho. No entanto, ainda que os enfermeiros saibam da importância desta atividade, grande parte não as coloca em prática devido ao aumento da demanda, à quantidade de pacientes, à falta de incentivos das instituições e até mesmo por comodismo.

Palavras-chave:Criança.Hospitalização.Ludoterapia.Enfermagem.Humanização da Assistência.
\end{abstract}

\begin{abstract}
This is an integrative literature review that aims to analyze and characterize what scientific studies published in journals of the 2010 year of health of the area to 2014 point about using playful during hospitalization of children. The survey was conducted from August to December 2014. In seeking to indexing databases SciELO, LILACS, the descriptors "play therapy" were used, "hospitalization" and "child" as directed by the Descriptors in Health Sciences Library Virtual Health. According to the articles analyzed can be seen that the playful is easy to apply and it is necessary to lessen or eliminate the traumas that hospitalization brings to the individual, with a practice that covers various forms ranging from the establishment of a conversation to the use of instruments such as the toy and the design. However, although the nurses know the importance of this activity, largely does not put them into practice due to increased demand, the amount of patients, lack of incentives for institutions and even for convenience.
\end{abstract}

Keywords: Child. Hospitalization.Play therapy.Nursing.Humanization of Assistance. 


\section{INTRODUÇÃO}

A hospitalização é um momento difícil na vida de qualquer indivíduo, no caso da criança pode se configurar como uma experiência traumática, pois proporciona a mesma, insatisfações momentâneas ou prejuízos que irão além da internação, bem como as afastam de sua vida cotidiana e do ambiente familiar colocando-as em um mundo diferente, constituído de equipamentos, pessoas desconhecidas, limitações de movimento, cheiros, procedimentos e dores. É um processo inevitável acarretador de sofrimento físico e psíquico, percebe-se que diante desse processo a criança interage e reage de forma diferente, por isso, torna-se relevante atentar para atividades de entretenimento proporcionadas às crianças hospitalizadas (AZEVÊDO,2013;MARTINEZ;

TOCANTINS; SOUZA, 2013; SOUZA et al., 2012).

Para que essas práticas possam ser consolidadas faz-se necessário modificar os modos de pensar e fazer saúde, não restringindo-se apenas as rotinas hospitalares ou a estrutura física, mas sim a interação com o paciente e seu acompanhante, articulando avanços tecnológicos com humanização da assistência, possibilitando assim ao seu acompanhante sentir-se sujeito nesse processo, já que a família/acompanhante é considerada uma das principais formas de amenizar os efeitos indesejáveis da hospitalização. Tendo em vista que não se deve colocar a criança como um ser isolado durante a hospitalização, pois esta faz parte de um núcleo familiar e de todo um contexto social, que direta e indiretamente pode influenciar nos períodos e características do cuidado $\quad$ (GOMES; $\quad$ ERDMANN; BUSANELLO, 2010; $\quad$ MARTINEZ; TOCANTINS; SOUZA, 2013; SIMÕES et al., 2010).

Segundo Santos et al. (2013), os pacientes quando hospitalizados tem direitos estabelecidos pela a Politica Nacional de Humanização (PNH) á uma melhor relação do profissional com o paciente e do hospital com a sociedade, objetivando uma melhora na qualidade dos serviços prestados. Além dos direitos assegurados pela a $\mathrm{PNH}$, todo hospital que oferece atendimento pediátrico em regime de internação, de acordo com a Lei 11.104 de 2005 , deve oferecer para a criança um espaço com jogos e brinquedos, nomeado de brinquedoteca, já que o ato de brincar é garantido no artigo 16, item IV do Estatuto da Criança e do Adolescente (ECA) (NICOLA et al., 2014).

A arte lúdica ou a ludoterapia é considerada uma estratégia de humanização, que aplica o brincar de diversas formas, esta atividade, deve ser utilizada diariamente pela equipe de saúde, pois possibilita ao indivíduo tanto uma continuidade do desenvolvimento infantil como a reintegração do bem-estar físico e emocional, resultando assim em uma 
hospitalização menos traumatizante, pois além de estabelecer uma interação entre a criança e o profissional da saúde, torna o ambiente no qual o sujeito está inserido mais agradável. Nesse contexto, a sua prática concede que o sujeito exponha sentimentos negativos frente à hospitalização, bem como a mudança de comportamento do sujeito (AZEVÊDO, 2013;CUNHA; SILVA, 2012; SIMÕES et al., 2010).

Este método, expressa-se de várias formas: brincadeiras, brinquedo terapêutico, descontrações, comunicação verbal ou não e outros. A comunicação é considerada um fator importante no direcionamento da assistência da equipe a saúde do indivíduo, contribui para o desenvolvimento e crescimento da criança; com relação à comunicação não verbal, esta pode ser facilitada pela a brincadeira, além de contribuir para o desenvolvimento psíquico do sujeito (concentração, memória, imaginação e outros). Porém o que importa não são os recursos tecnológicos utilizados e sim a humanização (DIAS et al., 2013;MARTINEZ; TOCATINS; SOUZA, 2013; NICOLA et al., 2014;).

Segundo Maia, Ribeiro e Borba (2011), o brincar é utilizado pela a equipe de enfermagem em três momentos: durante a rotina diária; no preparo dos procedimentos invasivos e durante a realização de procedimentos dolorosos e desagradáveis. O profissional de enfermagem que trabalha na ala de pediatria além de empatia deve ter criatividade e sensibilidade quando aproximar-se da criança doente, desta forma pode-se evidenciar a importância que o enfermeiro tem na amenização dos sofrimentos resultantes da hospitalização (SANTOS et al., 2013).

Desta forma o estudo teve por finalidade analisar e caracterizar o que as produções científicas publicadas em periódico da área da saúde do ano de 2010 a 2014, apontam acerca da utilização do lúdico durante a hospitalização de crianças.

\section{METODOLOGIA}

Para alcançar o objetivo proposto, selecionou-se como método para o presente estudo a revisão integrativa da literatura. A revisão integrativa se caracteriza como uma pesquisa científica que evidencia um assunto ou referencial teórico, sintetizando-o e esclarecendo sobre aspectos importantes acerca de determinados temas, a partir da análise de pesquisas de fontes primárias, secundárias, empírica, artigos publicados ou não em periódicos e literatura (MENDES; SILVEIRA; GALVÃO, 2008).

Para a construção de uma revisão integrativa é preciso passar por seis etapas distintas, que foram utilizadas neste estudo: identificação do tema e seleção da hipótese ou questão de pesquisa; estabelecimento de critérios para a inclusão e exclusão de estudos; definição das informações a serem 
extraídas dos estudos selecionados; avaliação dos estudos incluídos; interpretação dos resultados; apresentação do conhecimento.

A principal questão norteadora para elaboração da presente pesquisa consistiu-se em identificar o que os estudos trazem a respeito dessa temática em periódicos de interesse da saúde no ano de 2010 a 2014.

Este levantamento foi realizado no período de Agosto à Dezembro de 2014, nas seguintes bases de dados: LILACS (Literatura Latino-Americana e do Caribe em Ciências da Saúde),SciELO (Scientific Eletronic Lybrary On-line).

Para obtenção da amostra da revisão integrativa, foram cruzados os descritores do DECs(Descritores em Ciência da Saúde): Ludoterapia, Hospitalização e Criança. Estes foram utilizados com o operador booleano $A N D$, cruzando de forma combinada os descritores HospitalizaçãoandLudoterapia, e HospitalizaçãoandCriança.

Os critérios de inclusão estabelecidos foram os seguintes: serem artigos científicos publicados em periódicos nacionais, dentro do período delimitado para esta pesquisa, que foi do ano de 2010 a 2014, abordarem a temática do estudo e estarem disponíveis na íntegra, online.

Por critérios de seleção, foram excluídos da amostra: capítulos de livros, dissertações, teses, monografias, textos não científicos, artigos disponibilizados em outras línguas que não fosse à portuguesa e artigos científicos sem disponibilidade do texto na íntegra.

Para a seleção dos artigos, cada título e resumo foram lidos exaustivamente a fim de confirmar se o estudo se enquadrava ao objetivo elaborado para esta investigação e se atendia aos critérios de inclusão.

Desta maneira, ao consultar a base de dados SciELO, o cruzamento dos descritores Hospitalização e Ludoterapia resultaram em 1 artigo, porém este não foi selecionado, 6 no LILACS, nos quais selecionamos 2 , e ao combinar Hospitalização e Criança,no SciELO encontramos 32 artigos, mas apenas 1 foi utilizado. Já no LILACS resultou em 541 artigos, porém foram utilizados 14 artigos.

Ao término da investigação dos títulos nas bases de dados estes foram comparados, pois muitos artigos foram indexados em mais de uma base de dados, sendo incluídos apenas uma vez no estudo. Após o percurso da trajetória metodológica descrita, foram selecionadas publicações que contemplavam a pergunta norteadora desta revisão, bem como os critérios de inclusão previamente estabelecidos.

\section{RESULTADOS E DISCUSSÃO}

Todos os artigos foram lidos na íntegra e selecionados somente aqueles que incluíam os aspectos relacionados à hospitalização e ludoterapia. No primeiro momento, os artigos foram caracterizados quanto ao ano de 
publicação, local da revista onde foram publicados, local em que foi desenvolvido o estudo e perfil dos pesquisadores, tendo como referência seus títulos.

As publicações analisadas foram distribuídas ao longo dos anos de 2010 a 2014; o ano de 2010, se destacou com 10 artigos (59\%), seguido pelo o ano de 2012 com 3 artigos (17\%) e 2011 com 2 artigos (12\%), os anos de 2013 e 2014 apresentaram apenas 1 artigo (6\%) cada ano. Em relação aos periódicos nas quais foram publicados os estudos selecionados, a maioria era proveniente da Região Sudeste e CentroOeste do país, sendo a maioria da área de enfermagem. Quanto ao local onde ocorreram as pesquisas relatadas nos artigos analisados foi predominante a região Sudeste e CentroOeste com 14 estudos (82\%), procedida pela região Sul e Nordeste com 3 estudos (28\%).

De acordo com GIACCHERO e MIASSO(2006), a região sudeste destaca-se com um maior número de publicações cientificas devido ser a mais populosa do país e concentrar o maior número de universidades. Com relação ao elevado quantitativo de artigos científicos, o autor discorre que no Brasil no final da década de 70 e inicio da década de 80, houve um investimento nas publicações cientificas, porém devido a problemas econômicos na década de 80 , houve a diminuição destes investimentos, tendo um aumento dos investimentos em produções cientificas somente na década de 90. Com relação às produções cientificas de enfermagem essas desenvolveram-se a partir da década de 70.

Em relação aos autores, a maioria era da área de Enfermagem (81\%), o restante (19\%) incluía: psicólogos, médicos, fisioterapeuta, terapeuta ocupacional e pedagoga. Quase todos apresentavam algum vínculo com uma instituição de ensino, sendo que $16(41 \%)$ apresentava o título de graduado e 10 (25\%) o título de doutor.

Para facilitar a compreensão, elaborou-se um quadro com a identificação do estudo, ano de publicação, tipo de estudo, objetivo e base de dados, dos artigos selecionados para o desenvolvimento deste estudo. 
Quadro 1 - Distribuição dos estudos referente às atividades de educação em saúde segundo identificação do estudo, ano de publicação, tipo de estudo, objetivo, base de dados.

\begin{tabular}{|c|c|c|c|c|}
\hline Identificação do estudo (autores, título e periódico) & $\begin{array}{l}\text { Ano de } \\
\text { publicação }\end{array}$ & Tipo de estudo & Objetivo & $\begin{array}{l}\text { Base de } \\
\text { dados }\end{array}$ \\
\hline $\begin{array}{l}\text { Jansen MF, Santos RM, Favero L. Benefícios da utilização } \\
\text { do brinquedo durante o cuidado de enfermagemprestado à } \\
\text { criança hospitalizada. }\end{array}$ & 2010 & $\begin{array}{l}\text { Estudo qualitativo do } \\
\text { tipoexploratório- } \\
\text { descritiva. }\end{array}$ & $\begin{array}{lr}\text { Verificar os benefícios } & \text { da } \\
\text { utilização } & \\
\text { brinquedoterapêuticodurante } & \text { do } \\
\text { cuidado realizado pelos } \\
\text { acadêmicosde enfermagem à } \\
\text { criança hospitalizada. }\end{array}$ & SCIELO \\
\hline $\begin{array}{l}\text { Pinto JP, Ribeiro CA, Pettengill MAM. O processo de } \\
\text { recuperação da criança após a alta hospitalar:revisão } \\
\text { integrativa. }\end{array}$ & 2010 & $\begin{array}{l}\text { Revisão de literatura } \\
\text { do tipointegrativa. }\end{array}$ & \begin{tabular}{lrr} 
Identificar & \multicolumn{2}{r}{ oconhecimento } \\
disponível sobre o processo de \\
recuperaçãoda
\end{tabular} $\begin{array}{l}\text { criança } \\
\text { hospitalizada e de sua família } \\
\text { após a alta. }\end{array}$ & LILACS \\
\hline $\begin{array}{l}\text { Castro DP, Andrade CUB, Luiz E, Mendes M, Barbosa D, } \\
\text { Santos LHG. Brincar como instrumento terapêutico. }\end{array}$ & 2010 & $\begin{array}{l}\text { Investigação } \\
\text { qualiquantitativa. }\end{array}$ & $\begin{array}{lr}\text { Analisar } & \text { de } \\
\text { formaqualiquantitativa } & \text { os } \\
\text { benefícios do "Brincarcom } \\
\text { Instrumento Terapêutico" em } \\
\text { criançashospitalizadas. }\end{array}$ & LILACS \\
\hline $\begin{array}{l}\text { Silva ACM da, Silva MAda. As contribuições da arte } \\
\text { lúdicado restabelecimentoda saúde humana. }\end{array}$ & 2012 & Revisão integrativa & $\begin{aligned} & \checkmark \text { Sistematizar a produção } \\
& \text { científica nacional, no que } \\
& \text { se refere às contribuições } \\
& \text { da arte lúdica no } \\
& \text { restabelecimento da saúde } \\
& \text { humana; } \\
& \checkmark \text { Caracterizar a produção } \\
& \text { científica sobre o uso de } \\
& \text { técnicas lúdicas na } \\
& \text { recuperaçãoda saúde } \\
& \text { humana; técnicas } \\
& \checkmark \\
& \text { Descrever as nó } \\
& \text { lúdicas mais utilizadas no } \\
& \text { cotidiano hospitalar pelos }\end{aligned}$ & LILACS \\
\hline
\end{tabular}




\begin{tabular}{|c|c|c|c|c|}
\hline & & & $\begin{array}{l}\text { profissionais } \\
\text { trabalhadores da saúde: } \\
\text { Mostrar os benefícios da } \\
\text { terapia lúdica na } \\
\text { recuperação da saúde. }\end{array}$ & \\
\hline $\begin{array}{l}\text { Nicola GDO, Freitas HMB, Gomes GC, Costenaro RGS, } \\
\text { Nietsche EA, Ilha S. Cuidado lúdico à criança hospitalizada: } \\
\text { perspectiva do familiar cuidador e equipe de enfermagem. }\end{array}$ & 2014 & $\begin{array}{l}\text { Estudo exploratório, } \\
\text { descritivo de } \\
\text { abordagem } \\
\text { qualitativa }\end{array}$ & $\begin{array}{l}\text { Conhecer como o cuidado lúdico } \\
\text { vem sendo incorporado no fazer } \\
\text { dos profissionais de enfermagem e } \\
\text { do familiar cuidador durante a } \\
\text { hospitalização da criança. }\end{array}$ & LILACS \\
\hline $\begin{array}{l}\text { Simões ALA, Maruxo HB, Resende Yamamoto L, Da Silva } \\
\text { LC, Silva PA. Satisfação de clientes hospitalizados em } \\
\text { relação às atividades lúdicas desenvolvidas por estudantes } \\
\text { universitários. }\end{array}$ & 2010 & $\begin{array}{l}\text { Estudo exploratório } \\
\text { descritivo }\end{array}$ & $\begin{array}{l}\text { Caracterizar os clientes internados } \\
\text { noHC/UFTM segundo as } \\
\text { variáveis: sexo e idade everificar a } \\
\text { opinião destes clientes sobre } \\
\text { suasatisfação em relação às } \\
\text { atividades lúdicas realizadaspelos } \\
\text { integrantes do grupo } \\
\text { SARAKURA. }\end{array}$ & LILACS \\
\hline $\begin{array}{l}\text { Maia EBS, Ribeiro CA, Borba RIH. Compreendendo a } \\
\text { sensibilização do enfermeiropara o uso do brinquedo } \\
\text { terapêutico naprática assistencial à criança. }\end{array}$ & 2011 & $\begin{array}{l}\text { Estudo } \\
\text { Interacionismo } \\
\text { Interpretativo }\end{array}$ & $\begin{array}{l}\text { Compreender comoocorre a } \\
\text { sensibilização da enfermeira para } \\
\text { o uso do BT,como instrumento de } \\
\text { intervenção de enfermagem na } \\
\text { assistênciaà criança. }\end{array}$ & LILACS \\
\hline $\begin{array}{l}\text { Costa ÉB, Lima SS, Ferrari R. Dor em pediatria:o papel da } \\
\text { assistência de enfermagem junto à criança com dor. }\end{array}$ & 2012 & ------------------ & $\begin{array}{l}\text { Adquirir noções básicas sobre a } \\
\text { fisiologia da dor, as formas de } \\
\text { avaliação da dor na criaça. }\end{array}$ & LILACS \\
\hline $\begin{array}{l}\text { Marques K N. Assistência de enfermagem humanizada a } \\
\text { criança hospitalizada. São Paulo. }\end{array}$ & 2011 & Revisão bibliográfica & $\begin{array}{l}\text { Apresentar à equipe } \\
\text { deenfermagem a importância do } \\
\text { cuidado humanizadocom a criança } \\
\text { hospitalizada. }\end{array}$ & LILACS \\
\hline $\begin{array}{l}\text { Souza AB, Silva EDP. Métodos de amenização do } \\
\text { sofrimento provocado pela hospitalização infantil. }\end{array}$ & 2013 & Estudo Descritivo & 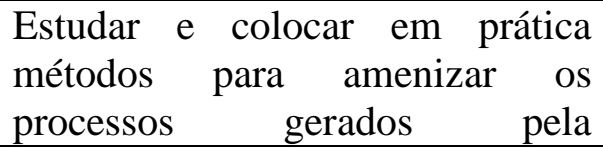 & LILACS \\
\hline
\end{tabular}




\begin{tabular}{|c|c|c|c|c|}
\hline & & & hospitalização infantil. & \\
\hline $\begin{array}{l}\text { Silva SH, Jesus IC, Santos RM. Humanização em Pediatria: } \\
\text { O brinquedo como recurso na assistência de enfermagem à } \\
\text { criança hospitalizada. }\end{array}$ & 2010 & $\begin{array}{l}\text { Revisão } \\
\text { Bibliográfica }\end{array}$ & $\begin{array}{l}\text { Conhecer melhor a criança e o } \\
\text { atendimento } \\
\text { humanizado a ela oferecido } \\
\text { atualmente. }\end{array}$ & LILACS \\
\hline $\begin{array}{l}\text { Fontes CMB; Mondini CCSD; Moraes MCAF; Bachega MI; } \\
\text { Maximino NP. Utilização do brinquedo terapêutico na } \\
\text { assistência à criança hospitalizada. }\end{array}$ & 2010 & $\begin{array}{l}\text { Estudo exploratório } \\
\text { descritivo }\end{array}$ & $\begin{array}{l}\text { Utilizar o brinquedo como recurso } \\
\text { terapêutico no alívio das tensões } \\
\text { reais e inconscientes da criança } \\
\text { em relação à hospitalização. }\end{array}$ & LILACS \\
\hline $\begin{array}{l}\text { Linhares MBM; Doca FNP. Dor em neonatos e crianças: } \\
\text { avaliação e intervenções não farmacológicas. }\end{array}$ & 2010 & |----------------- & |--------------------------------- & LILACS \\
\hline $\begin{array}{l}\text { Conceição CM, Ribeiro CA, Borba RIH, Ohara CVS; } \\
\text { Andrade PR. Brinquedo terapêutico no preparo da criança } \\
\text { para punção venosa ambulatorial: percepção dos pais e } \\
\text { acompanhantes. }\end{array}$ & 2011 & $\begin{array}{l}\text { Estudo descritivo } \\
\text { qualitativo }\end{array}$ & $\begin{array}{l}\text { Compreender a percepção de pais } \\
\text { e acompanhantes sobre o emprego } \\
\text { do Brinquedo Terapêutico no } \\
\text { preparo da criança para a punção } \\
\text { venosa ambulatorial. }\end{array}$ & LILACS \\
\hline $\begin{array}{l}\text { Francischinelli AGB, Almeida FA, Fernandes DMSO. Uso } \\
\text { rotineiro do brinquedo terapêutico na assistência a crianças } \\
\text { hospitalizadas: percepção de enfermeiros }\end{array}$ & 2012 & $\begin{array}{l}\text { Estudo descritivo- } \\
\text { exploratório, com } \\
\text { abordagem } \\
\text { quantitativa }\end{array}$ & $\begin{array}{l}\text { Identificar a percepção de } \\
\text { enfermeiros em relação aouso } \\
\text { rotineiro do brinquedo terapêutico } \\
\text { na assistência àcriança } \\
\text { hospitalizada. }\end{array}$ & LILACS \\
\hline $\begin{array}{l}\text { Silva FMAM, Silva SMM,Nascimento MDSB, Santos SM. } \\
\text { Cuidado paliativo: benefícios da ludoterapia em crianças } \\
\text { hospitalizadas com câncer. }\end{array}$ & 2010 & $\begin{array}{l}\text { Estudo } \\
\text { Ensaio clínico com } \\
\text { desenho } \\
\text { analítico } \\
\text { experimental pareado }\end{array}$ & $\begin{array}{l}\text { Analisar benefícios psicológicos } \\
\text { de um trabalho ludoterápico como } \\
\text { cuidadopaliativo em crianças } \\
\text { hospitalizadas com câncer. }\end{array}$ & LILACS \\
\hline
\end{tabular}




\begin{tabular}{|l|l|l|l|}
\hline $\begin{array}{l}\text { Lemos LMD, Pereira WJ,Andrade JS, AndradeASA. Vamos } \\
\text { cuidar com brinquedos? }\end{array}$ & 2010 & $\begin{array}{l}\text { Estudo exploratória } \\
\text { com abordagem } \\
\text { qualitativa }\end{array}$ & $\begin{array}{l}\text { Identificar a percepção da equipe } \\
\text { deenfermagem quanto o preparo } \\
\text { de crianças e adolescentes para } \\
\text { procedimentos hospitalares em } \\
\text { um hospital Universitário de } \\
\text { Aracaju. }\end{array}$ \\
\hline
\end{tabular}

Fonte: Dados da pesquisa. 
Tem-se conhecimento dos inúmeros benefícios do lúdico, inclusive como cuidado paliativo para crianças com câncer,pois torna os momentos e situações bem menos traumáticos e ajuda reestabelecer a autoestima, tornando-se essencial por desenvolver habilidades de linguagem, psicológicas e motoras. Em alguns casos temse um ambiente propenso para o desenvolvimento de atividades lúdicas, porém para determinados hospitais é apenas um local onde a criança e sua mãe assistem televisão ou na maioria das vezes tem-se o local, mas a criança juntamente com seu familiar utiliza sem um profissional capacitado para a essa sistematização, tornando um ambiente propenso a angustias. Além disso, sua prática está relacionada também ao interesse e conhecimento dos profissionais em colocar em prática no seu cotidiano hospitalar (CASTRO et al., 2010; FRANCISCHINELLI; ALMEIDA; FERNANDES, 2012; LEMOS et al.; 2010; SILVA et al., 2010).

Simões et al. (2010) relata que o grupo SAKAMURA aplicava diversas atividades lúdicas, entre elas destaca-se: conversas, brincadeiras, música e leitura; que tinham a finalidade de prestar uma assistência humanizada na qual promovesse bem estar aos pacientes e familiares contribuindo para amenizar o sofrimento destes, além disso, facilita o processo terapêutico, fazendo com que os pacientes encarem a hospitalização de forma menos dolorosa e expressem seus sentimentos e angustias. A Iniciativa do grupo SAKAMURA ainda mostra a importância da participação das extensões universitárias juntamente com a equipe multiprofissional do hospital melhorando a qualidade da assistência a estes pacientes.

Já no estudo de Maia, Ribeiro e Borba (2011), a forma lúdica utilizada é o Brinquedo Terapêutico (BT), no qual deve ser utilizado pelos profissionais de enfermagem, pois gera um vínculo de afeto e confiança entre a criança e o enfermeiro facilitando o cuidado prestado. Uma vez que os pacientes interagem melhor com a equipe, diminuindo sua ansiedade, encarando de maneira menos dolorosa o processo de adoecimento. Marques (2011) ainda complementa afirmando que a utilização do brinquedo terapêutico é uma forma não direta de brincar e que pode servi também para demonstrar procedimentos, facilitando a compreensão da assistência prestada.

Com relação ao uso do BT pelos profissionais de enfermagem, o Conselho Federal de Enfermagem (COFEN) e o Conselho Regional de Enfermagem de São Paulo (COREN-SP) defendem a abordagem do BT na graduação, sendo que alguns professores já abordam o brinquedo terapêutico nas aulas, pois acreditam que é um instrumento importante no cuidado de enfermagem e que cabe principalmente ao enfermeiro incentivar o uso do BT e motivar a 
criançae a família a participarem das atividades propostas.(JANSEN; SANTOS; FAVERO, 2010; SILVA et al., 2010)

Conceição et al. (2011), descreve sobre o uso da atividade lúdica em discussão durante a punção venosa, no qual prepara a criança para não ter uma controvérsia espantosa do procedimento e auxilia o profissional da saúde principalmente o enfermeiro a tal procedimento. Como consequência desse procedimento as crianças são mais calmas controlam melhor os seus medos diminuindo o tempo da pulsão, deste modo o brinquedo terapêutico foi colocado pelo autor como fazendo parte da sistematização da enfermagem.

Fontes et al. (2010), ao realizar a sua pesquisa com o intuito de observar em dois momentos como as crianças hospitalizadas ao terem contato com o brinquedo reagiam, percebeu que:a metade manipularam os brinquedos nos dois momentos; no primeiro momento a maioria das crianças não manifestou interesse em brincar ou realizar alguma intervenção, porém no segundo momento ocorreu uma maior interação das crianças com os brinquedos e o cenário lúdico; a maioria realizoua negociação e compartilhamento do brinquedo com outras crianças, a maioria questionou durante $\mathrm{o}$ primeiro momento e que metade vestiram as roupas cirúrgicas nos dois momentos.

O estudo de Linhares e Doca (2010) é sobre dor em neonatos e criança, as autoras discorrem sobre algumas técnicas de intervenção não-farmacológica em criançaspara o alívio ou eliminação da dor, as quais são: cognitivo-comportamentais; distração isoladamente ou combinada; hipnose; além disso destacam algumas atitudes que devem ser evitadas pelo o profissional, pois podem intensificar a dor da criança ou do adolescente, as quais são: mentir, ridicularizar a criança, potencializar a dor e depositar na criança expectativas elevadas de força e coragem.

Para Costa, Lima e Ferrari(2012) é necessário que o profissional de enfermagem tenha conhecimento fisiopatológico da dore saiba aplicar a escala de avaliação, uma vez, que quando se trata de criança o processo de identificação e avaliação da dor torna-se difícil, pois nem todas já sabem expressar verbalmente a dor.

Silva e Silva (2012) em seu estudo aborda a importância da arte lúdica, as autoras destacam que, este tipo de atividade melhorando a qualidade de vida dos pacientes por proporcionar momentos de divertimento, alegria e distração. Nicola et al. (2014) complementa afirmando que, os familiares e os profissionais reconhecem os benefícios causados por esta atividade.

No segundo momento, a leitura dos artigos permitiu evidenciar as principais convergências encontradas, que foram sintetizadas, agrupadas e categorizadas, permitindo a elaboração de três categorias, 
nas quais são:os benefícios do lúdico para a criança, a prática do lúdico pelos os profissionais da saúde, as diversas formas de se aplicar o lúdico.

\section{CONCLUSÃO}

A hospitalização é vista como uma situação traumatizante para todos os indivíduos independentemente da sua idade, seja devido: ao tempo de internação, à insegurança, medo, ao ócio, à vulnerabilidade, ao distanciamento dos familiares, ao ambiente desconhecido, à perca da privacidade e aos procedimentos realizados que geralmente são dolorosos.

Desta forma percebeu-se que o lúdico é de fácil aplicação e se faz necessário para amenizar ou eliminar este momento difícil, sendo uma prática que abrange diversas formas variando desde o estabelecimento de uma conversação até o uso de instrumentos como o brinquedo e o desenho. Essas atividades no ambiente hospitalar são utilizadas pelo profissional da saúde, a fim de facilitar a assistência e contribuir de forma direta para um cuidado humanizado.

Durante a leitura dos artigos componentes desse estudo, identificou-se que, por mais que os enfermeiros saibam da importância desta atividade, grande parte não as coloca em prática devido ao aumento da demanda, à quantidade de pacientes, à falta de incentivos das instituições e até mesmo por comodismo.
Neste contexto compreende-se a necessidade de enfatizar durante a graduação dos profissionais da área da saúde, a importância da humanização, resultando assim na modificação da imagem negativa que a hospitalização representa para o indivíduo,além de contribuir para a nossa reflexão sobre a vulnerabilidade das crianças e a necessidade de prestar uma assistência com qualidade, visto que os traumas que se passam na infância influenciam na construção da personalidade do indivíduo.

\section{REFERÊNCIAS}

AZEVEDO, N. D. et al. Cuidado de enfermagem a famílias de crianças hospitalizadas por doença crônica.

CiencCuidSaude, v.11,n.3, p.522-28, Jul-Set, 2012. Disponível em: <http://www.periodicos.uem.br/ojs/index. php/CiencCuidSaude/article/view/20260/pdf> Acessado em: 1 Ago. 2014.

CASTRO, D. P.et al. Brincar como instrumento terapêutico. Pediatria, São Paulo, v.32, n.4, p.246-54, 2010. Disponível em:<http://www.fen.ufg.br/fen_revista/v10/n1 /v10n1a12.htm >. Acessado em:7 Ago. 2014.

CONCEIÇÃO, C. M. et al. Brinquedo terapêutico no preparo da criança para punção venosa ambulatorial: percepção dos pais e acompanhantes.Esc Anna Nery, Rio de Janiero, v.15, n.2, p.346-53, abr. -jun., 2011. 
Disponível em:

$<$ http://www.scielo.br/scielo.php?script=sci_a rttext\&pid=S1414-81452011000200018> . Acessado em: 15 Ago. 2014.

COSTA, E. B.; LIMA, S. S.; FERRARI, R. Dor em pediatria: o papel da assistência de enfermagem junto à criança com dor. Rev. Eletr. Gestao\&Saude, Brasília, v.3, n.3, p.1179-188, 2012. Disponível em: $<$ http://gestaoesaude.unb.br/index.php/gestaoe saude/article/view/203>. Acessado em:7 Ago. 2014.

CUNHA, G. L.; SILVA, L. F. Lúdico como recurso para o cuidado de enfermagem pediátrica na punção venosa. Rev Rene, v.13, n.5, p.1056-1065, 2012. Disponível em <http://www.revistarene.ufc.br/revista/index.ph p/revista/article/view/49/pdf> Acessado em: 1 Ago. 2014.

DIAS, J. J. et al. A experiência de crianças com câncer no processo de hospitalização e no brincar. Rev Min Enferm, v.17, n.3 p.608-613, Jul-Set, 2013. Disponível em <http://www.reme.org.br/artigo/detalhes/676> Acessado em: 3 Ago. 2014.

FONTES, C. M. B. et al. Utilização do brinquedo terapêutico na assistência à criança hospitalizada. Rev. bras. educ. espec., São Paulo, v.16, n.1, p. 96-105, Jan.- Abr. 2010. Disponível em: $<$ http://www.scielo.br/scielo.php?script=sci_a
rttext\&pid=S1413-65382010000100008>

Acessado em: 20 Ago. 2014.

FRANCISCHINELLI, A. G. B.; ALMEIDA, F. A.; FERNANDES, D. M. S. O. Uso rotineiro do brinquedo terapêutico na assistência a crianças hospitalizadas: percepção de enfermeiros. Acta Paul

Enferm. São Paulo, v.25, n.1, p.18-23, 2012. Disponível em:

$<$ http://www.scielo.br/scielo.php?script=sci_a rttext\&pid=S0103-21002012000100004>. Acessado em: 15 Ago. 2014.

GIACCHERO, K. G.; MIASSO, A. I. A produção científica na graduação de enfermagem (1997 a 2004): análise crítica. Revista Eletrônica de Enfermagem, Goiânia, v.8, n.3, p.431-40, 2006. Disponível em:<https://www.revistas.ufg.br/index.php/fe n/article/view/7082>. Acessado em: 22 Mar. 2015.

GOMES, G. C.; ERDMANN, A. L.; BUSANEL, J. Refletindo sobre a inserção da família no cuidado à criança hospitalizada.

Rev. enferm, Rio de Janeiro, v.18, n.1, p.14347, Jan.-Mar., 2010. Disponível em <http://repositorio.furg.br/handle/1/1540>Ace ssado em:1 Ago. 2014.

JANSEN, M. F.; SANTOS, R. M.; FAVERO, L. Benefícios da utilização do brinquedo durante o cuidado de enfermagem prestado à criança hospitalizada. Rev. GauchaEnferm, Porto Alegre - RS, v.31, n.2, p.247-53, Jun., 
2010. Disponível

em:<http://www.scielo.br/pdf/rgenf/v31n2/07. pdf > Acessado em: 19 Ago. 2015.

LEMOS, L. M. D. et al. Vamos cuidar com brinquedos?RevBrasEnferm, Brasília; v.63, n.6, p.950-5, Nov.- Dez., 2010. Disponível em:

<http://www.scielo.br/scielo.php?pid=S0034$71672010000600013 \&$ script $=$ sci_arttext $>$.

Acessado em:7 Ago. 2014.

LINHARES, M. B. M.; DOCA, F. N. P. Dor em neonatos e crianças: avaliação e intervenções não farmacológicas.Temas em

Psicologia, Ribeirão Preto, v.18, n.2, p. 307 25, 2010. Disponível em: $<$ http://pepsic.bvsalud.org/scielo.php?pid= S1413389X2010000200006\&script=sci_artte xt> Acessado em: 20 Ago. 2014.

MARTINEZ, E. A.; TOCANTINS, F. R.;

SOUZA, S. R. As especificidades da comunicação na assistência de enfermagem à criança. RevGauchaEnferm, v.34, n.1, p.3744, 2013. Disponível em:

$<$ http://www.scielo.br/pdf/rgenf/v34n1/05.pdf > Acessado em:3 Ago. 2014.

MENDES, K. D. S; SILVEIRA, R.C.C. P.; GALVÃO, C.M. Revisão integrativa: método de pesquisa para a incorporação de evidências na saúde e na enfermagem. Texto Contexto Enferm. 2008; v.17, n.4, p. 758-64.
MAIA, E. B. S.; RIBEIRO, C. A.; BORBA, R. I. H. Compreendendo a sensibilização do enfermeiro para o uso do brinquedo terapêutico na prática assistencial à criança. Rev. Esc.Enferm. São Paulo, v.45, n.4, p.83946, 2011. Disponível em:

$<$ http://www.scielo.br/scielo.php?script=sci_a rttext\&pid=S0080-62342011000400007 > Acessado em:10 Set. 2014.

NICOLA, G. D. O. Cuidado lúdico à criança hospitalizada: perspectiva do familiar cuidador e equipe de enfermagem. Rev.

fundam. care. Online, Rio de Janeiro, v.6, n.2, p.703-715, abr./jun., 2014. Disponível em <http://www.seer.unirio.br/index.php/cuidado fundamental/article/viewFile/3079/pdf_1269 > Acessado em: 7 Ago. 2014.

SANTOS, M. R. et al. Desvelando o cuidado humanizado: percepções de enfermeiros em oncologia pediátrica.Texto Contexto

Enferm, Florianópolis, v.22, n.3, p.646-53, Jul-Set, 2013. Disponível em:<http://www.scielo.br/pdf/tce/v22n3/v22n3 a10.pdf> Acessado em: 1 Ago. 2014.

SILVA, A. C. M. da; SILVA, M. A. da. As contribuições da arte lúdica do restabelecimento da saúde humana. Estudos, Goiânia, v.39, n. 4, p. 469-480, Out-Dez.

2012. Disponível em: $<$ http://seer.ucg.br/index.php/estudos/article/v iewArticle/2661 > Acessado em: 10 Set. 2014 
SILVA, F. M. A. M. et al. Cuidado paliativo:

benefícios da ludoterapia em crianças

hospitalizadas com câncer. Bol. Acad.

Paulista de Psicologia, São Paulo, v. 78, n.1,

p.168-83, 2010. Disponível em:

$<$ http://www.redalyc.org/articulo.oa?id=9461

5157012 >. Acessado em: 15 Ago. 2014.

SIMÕES A. L. A. et al. Satisfação de clientes hospitalizados em relação às atividades

lúdicas desenvolvidas por estudantes

universitários. Rev. Eletr. Enf. Goiânia, v.12, n.1, p.107-12, 2010. Disponível em:

<http://www.fen.ufg.br/revista/v12/n1/v12n1a

13.htm >. Acessado em: 1 Set. 2014.

SOUZA, A. B. de; SILVA E. D. de P.

Métodos de amenização do sofrimento

provocado pela hospitalização infantil.

Perspectivas Médicas, São Paulo, v. 24, n. 1,

p.31-3, Jan.-Jun.,2013. Disponível em:

<http://www.redalyc.org/articulo.oa?id=2432279

44006>. Acessado em: 7 Ago. 2014. 